ESJ Social Sciences

\title{
Efficiency and Productivity Evaluation of the Moroccan Judicial System
}

\author{
Yassine Achenchabe \\ Mohammed Akaaboune \\ Faculty of Economic, Legal, and Social Sciences \\ Mohammed V University, Rabat, Morocco
}

Doi:10.19044/esj.2021.v17n27p282

Submitted: 01 June 2021

Accepted: 26 July 2021

Published: 31 August 2021
Copyright 2021 Author(s)

Under Creative Commons BY-NC-ND

4.0 OPEN ACCESS

Cite As:

Achenchabe Y. \& Akaaboune M. (2021). Efficiency and Productivity Evaluation of the Moroccan Judicial System. European Scientific Journal, ESJ, 17 (27), 282.

https://doi.org/10.19044/esj.2021.v17n27p282

\begin{abstract}
This paper focuses on measuring the efficiency and productivity change in 110 Moroccan courts between 2013 and 2018, which is the period of implementation of the judicial reform. The study also measures the technical and scale efficiency using the Data Envelopment Analysis method under output orientation. The Malmquist index was used to measure the productivity change decomposed into efficiency and technical change. The results show a low level of courts efficiency of $53.2 \%$, with increasing returns to scale for most courts except administrative ones. The total factor productivity of courts shows an improvement of $6.3 \%$, mainly due to technical change, except for the commercial courts whose productivity deteriorated during the study period. These results show the positive effect of the reform. Courts still have a margin for improving their efficiency by increasing inputs in order to benefit from economies of scale or by improving judges' productivity.
\end{abstract}

Keywords: Efficiency, Judicial system, Data Envelopment Analysis, Malmquist index, Productivity change

\section{Introduction}

The judicial system is a factor of governance and impetus for development, and it plays a significant role in the functioning of the economy. 
Thus, a positive correlation is recognized between the performance of a country's judicial system and its economic growth (World Bank, 2003), investment activities, the availability of financing, and the size of companies (Dam, 2006).

However, this system may suffer from several dysfunctions which influence citizens' access to justice such as congestion (Rosales-Lopez, 2008), the cost and delay of procedures (Dalla Pellegrina, 2008), or even the lack of incentives to increase judges' productivity (Schneider, 2005).

As a result, Morocco have become more aware of the importance of the judicial system and has launched a national dialogue on judicial reform in 2012 , which resulted in the establishment of a reform charter that represents the strategy for the period 2013-2020.

Implementing this reform requires the mobilization of significant human and financial resources, whether to improve the judges' and clerks' salaries or for investment in infrastructure and modernization of courts. Thus, this brought the budget allocated to the system to $1.6 \%$ of the general state budget.

Therefore, this study aims to analyze the efficiency and measure the productivity change of Moroccan courts during the period of implementation of the national charter of judicial reform between 2013 and 2018.

To achieve this, Data Envelopment Analysis method was used to measure efficiency. This is a recognized method used in literature that evaluates the performance of decision-making units. The main positive feature of this method concerns the relaxed assumptions on input-output data distribution and the non-specification of the technological frontier (Cooper et al., 2001). However, some limitations are mentioned such as the production of sensitive results and measurement errors since any distance from the efficiency frontier is attributed to inefficiency (Simar \& Wilson, 2015).

The DEA method was used under output orientation, with the assumption of variable returns to scale VRS, to measure the efficiency of 110 Moroccan courts between 2013 and 2018. These courts were divided into four groups to avoid the problem related to the heterogeneity of cases treated by each type of court. These groups are constituted by the appeal courts, first instance courts, commercial courts, and administrative courts. As with most previous studies, the number of judges, clerks, and staff costs was used as inputs while the number of cases resolved represented outputs. Furthermore, the Malmquist index was used to measure productivity change during the same period so as to distinguish between efficiency change and technical change.

Hence, this study contributes to a better understanding of the effect of judicial reform on the Moroccan court's efficiency and productivity. More so, inefficient courts and their reference group are identified so that they can align to improve their efficiency. It is worthy to note that this study is the first to 
analyze the efficiency of Moroccan courts. It thus constitutes a reference for judicial managers to facilitate decision-making concerning the allocation of human and financial resources.

This paper is structured as follows: Section 2 presents a comprehensive literature review of the measurement of efficiency in the public sector, empirical studies on efficiency, and productivity change in the courts. Section 3 introduces the methodology, specifying the assumptions of the methods and the data used. Section 4 presents and explains the results of the efficiency and productivity change of the Moroccan courts, and Section 5 concludes by underlying the main findings of this study.

\section{Literature Review}

\subsection{Measuring Efficiency in the Public Sector}

The literature review illustrates that the production theory provides a methodological framework for measuring the efficiency of non-profit organizations through the input-process-output approach (Johnes, 1996). The concepts of efficiency and productivity are often associated in the literature, and these two terms have been used interchangeably in many contexts (Sherman \& Zhu, 2006). They are also the two most important concepts in the measurement of productivity performance. Their measurement can provide valuable information about the performance of the organization.

Several authors (Debreu, 1951; Koopman, 1951; Johnes, 1996; Coelli et al., 2005) have addressed the definition of efficiency and its decomposition in technical, allocative, or scale efficiency. The standard literature on efficiency measurement and the concept of the production frontier was initiated by Farrell (1957) based on the work of Debreu (1951) and Koopman (1951). These studies focus on the production done by entities called "Decision Making Unit" (DMU), which transforms inputs into outputs.

The same work distinguishes two components of economic efficiency: technical efficiency and allocative efficiency. Their combination can provide a measure of total economic efficiency. Also, the literature reveals that the efficiency of a decision-making unit can be obtained from two perspectives: an input orientation to reduce the inputs or an output orientation to increase the outputs.

Several methods that measure efficiency are reported in the literature, and the choice among them depends on the purpose of measurement and the availability of data. It is also possible to use conventional methods such as performance indicators since parametric or non-parametric methods can be used for production frontier analysis.

The difference between the two types of methods is that the parametric or statistical approach assumes a particular form of the production frontier. In contrast, the non-parametric approach makes no assumptions about the 
distribution of inefficiencies or the functional form of the production frontier (Johnes, 2006).

In the context of the public sector, a non-parametric approach called Data Envelopment Analysis (DEA) has been widely used in studies to measure efficiency and productivity (Johnes, 2006). The use of this method is due to its ability to consider several inputs and outputs, which is adequate for nonprofit organizations.

Thus, measuring efficiency by using the DEA method makes it possible to estimate the efficiency of a DMU compared to a benchmark. However, this measurement does not give an overview of the evolution of efficiency over time. This is why several authors (Fare et al., 1994; Coelli, 1996; Coelli \& Prasada Rao, 2005) have been interested in measuring productivity change, which allows monitoring changes in efficiency and assessing the impact of strategic decisions or public policies.

\subsection{Studies on the Use of DEA and Malmquist Index}

The review of studies using the DEA method clearly confirms the great interest shown by researchers in this method. According to Liu et al. (2013), even thirty years after the publication of the seminal paper by Charnes et al. (1978), development continues and has not seen signs of weakening. This method is also used to measure the efficiency of DMUs in different sectors of activity.

The DEA method is used by majority of studies in the education sectors, especially universities (Lim \& Md. Taib, 2016; Arjomandi et al., 2015), the health sector through the measurement of hospitals' efficiency, the banking sector, and other sectors.

Regarding the justice sector, only 29 studies measuring the efficiency of courts through the DEA method have been carried out between 1982 and 2019. This is confirmed by Voigt (2016) who stated that few studies have addressed the technical efficiency of judicial systems. This may be due to the lack of interest shown by researchers in cost-related studies in the justice sector compared to those concerned with judicial decisions quality (RosalesLopez, 2008).

This issue can be explained by the lack of data, which hinders the development of efficiency measurement studies in judicial systems (RosalesLopez, 2008; Finocchiaro Castro \& Guccio, 2014). This is even more restrictive in developing countries where information systems do not provide reliable data over several years. In addition, studies that focus on efficiency in the justice sector are conducted more in developed countries. At the same time, the African continent, for example, has minor efficiency studies in the courts (Voigt, 2016). 
The literature review also illustrates that most studies which focused on efficiency measurement in the justice sector used the DEA method. Furthermore, most of them were national in scope and focused mainly on the factors impacting judicial efficiency.

Most of the studies that used the DEA method had the objective of measuring the efficiency of the courts in order to detect those that are inefficient and to identify their benchmark (Nissi et al., 2019; Major, 2015; Yeung \& Azevedo, 2011; Pedraja-Chaparro \& Salinas-Jimenez, 1996). In this context, the study of Nissi and Rapposelli (2011) aimed to investigate whether the dysfunctions of Italian courts represented by the pending cases, judgments delays, and costs can be attributed to a non-optimal court size or an unfortunate combination of inputs. On the other hand, Kittelsen and Forsund (1992) tried to suggest efficiency-enhancing actions to observe whether the methods used to calculate efficiency are adapted to the public sector.

Regarding the DMUs chosen and the period of the studies, it is evident that most studies on the efficiency measurement have focused on the first instance courts. Thus, Yeung and Azevedo (2011) used data from 27 Brazilian first instance courts and appeal courts to measure their efficiency for the year 2008. Also, Tsai and Tsai (2010) studied the efficiency of 18 first instance courts in Taiwan. Elbialy and Garcia-Rubio (2011) used data from 22 first instance courts in Egypt, while Ferrandino (2012) focused on 20 courts in Florida for 15 years.

Most studies using the DEA method have opted for the output orientation since the courts can control the inputs (Tsai Tsai, 2010). On the other hand, the inputs and output chosen are almost the same for all studies. The selected inputs are often labor, capital, and equipment. However, the choice of outputs has been limited to judgments and judicial decisions.

The results of DEA studies in the justice sector reveal that it is possible to save inputs or increase outputs for most of the courts studied, and thus reduce pending cases (Major, 2015; Pedraja-Chaparro \& Salinas-Jimenez, 1996; Lewin et al., 1982). Through the results, it becomes easier to identify the courts with the best practices for benchmarking (Nissi \& Rapposelli, 2011).

On the other hand, the study conducted by Yeung and Azevedo (2011) has confirmed that courts operate under decreasing returns to scale, which leads to a loss of efficiency due to the inadequacy of production scale.

Yeung and Azevedo (2011) study confirm that the lack of human and financial resources cannot be considered as a cause of inefficiency, and the courts' efficiency is positively correlated with management performance. The study of Schneider (2005) provides a deeper analysis which states that courts employing more doctoral-level judges are more productive but have judgments less confirmed by the Supreme Court. Also, courts employing 
judges with a high probability of promotion are less productive. According to Ippoliti and Tria (2020), the North of Italy emerges more efficient than the other Italian macro-areas and improvements in court performance could be achieved by reforming civil procedures.

Concerning studies relating to the use of the Malmquist index, Falavigna et al. (2018) analyzed the productivity change of 103 Italian first instance courts between 2009 and 2011 and found that the reduction in the number of sections negatively impacted efficiency and the use of technology cannot replace the productivity of judges. Similarly, Mattsson et al. (2018) noted the negative change in Total factor productivity of 48 Swedish courts between 2012 and 2015, while Yeung (2018) noted a slight improvement in the efficiency of 27 Brazilian courts between 2009 and 2015. This underlines that the human and technological resources invested in courts have not improved the efficiency of the courts. More recently, Giacalone et al. (2020) analyzed the efficiency of the individual Italian judicial offices while assessing productivity progress from 2011 to 2016 . The results highlighted a distinct heterogeneity among courts, depending on their geographical location, and revealed that the judicial efficiency indicators during the study period are roughly equivalent.

This implies that the use of the DEA method in the field of the judicial sector provides a better understanding of the efficiency of the courts, identifies the benchmarks, and encourages the least efficient courts to increase their productivity or reduce their inputs. In the same perspective, some authors have tried to combine the DEA method with parametric techniques such as the stochastic frontiers analysis (SFA) or the Tobit regression to identify the determinants of efficiency and the environmental variables that influences the size of the DMU.

This review of the empirical studies carried out in the judicial systems also identifies a particular gap that constitutes lines of research for this empirical study. Accordingly, only one study has dealt with measuring the efficiency of the courts in an African country (El Bialy, 2011), and no study has treated the efficiency of the Moroccan judicial system. In addition, the scope of the majority of studies has been restricted to one type of court, i.e., the Appeal Courts or the First Instance Courts. This indicates the relevance of studying and comparing the efficiency of different types of courts.

\section{Methodology}

The DEA method was used to measure the efficiency of the 110 Moroccan courts for 2013 and 2018. These courts are part of a Moroccan judicial system that has undergone a set of reforms since the era of independence, especially the consecration that took place in 2011 for the independence of the judiciary in the new constitution and the establishment of 
two new institutions (Supreme Council of the Judicial Power and Presidency of the Public Prosecution) that manage judicial affairs. The Ministry of Justice, which comes under the executive power, retained the attributions relating to the legislative aspect and the administrative and financial management of the courts.

The organization of the Moroccan judicial system is overseen by the Court of Cassation and is composed of 110 common law jurisdictions, as well as jurisdictions specialized in administrative or commercial matters. During the study period, there were 21 appeal courts, 69 first instance courts, 2 administrative appeal courts, 3 commercial appeal courts, 7 administrative courts, and 8 commercial courts.

The choice of the study period was based on the context of the Moroccan judicial system, which underwent a broad modernization reform from the year 2013. More so, faced with the different demands of citizens to have fair and efficient justice, the King of Morocco ordered the creation of a High Commission for the National Dialog on the Reform of the Judiciary System. The work of this commission led to the preparation of a national reform charter in 2013, with 6 main objectives and more than 353 actions that were executed until 2020. This reform establishes the interest in measuring the efficiency of courts during the five years of implementation of the charter.

In this study, the output-oriented DEA method was used because the Moroccan jurisdictions suffer from problems linked to the slowness of processing and the large stock of pending cases, which makes it more favorable to opt for maximizing outputs than minimizing inputs.

The DEA BCC model was utilized under the VRS assumption to measure the efficiency of each group of courts separately. This model is more suitable for the courts' case since it is a monopoly system that is difficult to operate on an optimal scale. Furthermore, affairs' peculiarity suggests a distinct analysis to draw an efficiency frontier for each courts' group.

Through the DEA method, it is possible to distinguish each group of courts between pure technical efficiency and scale efficiency. The reference lists for inefficient courts can also be identified as well as the possible productivity gains. Good attention was given to outliers and extreme values to avoid error measurement of the DEA method. However, it is difficult to identify the productivity change throughout the implementation of judicial reform using the analysis of the DEA method. This is why the Malmquist productivity index is applied, which is proposed by Fare et al. (1994) to measure the productivity change.

It is possible to identify efficiency change using Malmquist index so as to determine the extent to which courts approach the efficiency frontier and technical or technological change, which concerns efficiency frontier 
movement. This movement may be due to the accumulation of experience, improved production techniques, or processes innovation.

\subsection{Assumptions of Data Envelopment Analysis and Malmquist Index 2.1.1. Assumptions of DEA Method}

The Data Envelopment Analysis (DEA) method is a non-parametric method that measures efficiency using linear programming. Charnes et al. (1978) introduced this method to measure the efficiency of a set of units called Decision-making units (DMU) by constructing a border enveloping all the possible combinations of inputs and outputs for each DMU.

The DEA method was developed based on Farrell's research, which defined the relative efficiency of decision-making units based on their distance from the efficient border. He further proposed a model by taking into account only a single input and a single output. Subsequently, Charnes et al. (1978) developed a model which allows the consideration of several inputs and outputs simultaneously.

Subsequently, two basic models have been proposed as part of the DEA method. The first is the CCR model (Charnes et al., 1978), which assumes that the units operate under constant returns to scale (CRS). The second is the BCC model (Banker et al., 1984) which assumes variable returns to scale (VRS).

The basic DEA CCR model, also known in the literature as the CRS model, is focused on an input orientation, i.e., the minimization of inputs for a given level of outputs, and on the assumption of constant returns to scale (CRS). This model is appropriate when the units operate in an environment of perfect competition and at an optimal size.

The efficiency scores generated by the CCR model combine both scale and technical efficiency. This model is thus unable to provide information on the extent to which the identified inefficiency may be due to technical or scale inefficiency.

This is why Banker et al. (1984) proposed the BCC model to extend and deepen the initial CCR model by adopting the hypothesis of variable returns to scale (VRS). Thus, this allows the efficiency to be decomposed in a technical part due to the scale.

The study considers a set of $n$ DMUs that consume m input to produce s outputs. Based on the rating proposed by Johnes (2004), the technical efficiency of a DMU k, as defined by Charnes et al. (1978), is measured by the ratio between the weighted sum of the outputs and that of the inputs:

$$
T E_{k}=\frac{\sum_{r=1}^{s} u_{r} y_{r k}}{\sum_{i=1}^{m} v_{i} x_{i k}}
$$


Where:

$T E_{k}$ : Technical efficiency of a DMU k using m input to produce $\mathrm{s}$ output $y_{r k}$ : Quantity of output $\mathrm{r}$ produced by the DMU k

$x_{i k}$ : Quantity of input i consumed by the DMU k

$u_{r}$ : Weight of the output $r$

$v_{i}$ : Weight of the input $\mathrm{i}$

$\mathrm{s}$ : Number of outputs

m: Number of inputs

The technical efficiency of each DMU is maximized under certain conditions (Johnes, 2004). Firstly, the weights of the outputs and inputs of the DMU k cannot generate an efficiency score greater than 1 (equation 3). Secondly, the weights applied to outputs and inputs are strictly positive (equation 4). For each DMU, the following linear programming problem has to be solved by maximizing the ratio $T E_{k}$ such as:

$$
\operatorname{MAX} \frac{\sum_{r=1}^{s} u_{r} y_{r k}}{\sum_{i=1}^{m} v_{i} x_{i k}}
$$

Under constraints:

$$
\begin{array}{lr}
\frac{\sum_{r=1}^{s} u_{r} y_{r k}}{\sum_{i=1}^{m} v_{i} x_{i k}} \leq 1 & j=1, \ldots, n \\
u_{r}, v_{i}>\mathbf{0} & \forall r=1, \ldots, s ; i=1, \ldots, m
\end{array}
$$

Where:

$\mathrm{k}$ : DMU for which efficiency is measured;

$\mathrm{j}$ : The DMUs studied.

Two approaches are possible to solve this linear programming problem. They are the input-oriented model, where the weighted sum of the inputs is minimized by keeping the outputs constant, and the output-oriented model, which will be the focus of this study, where the weighted sum of the outputs is maximized while maintaining constant the inputs.

Thus, the primal equation for the output-oriented VRS model to be used in this research is presented below. It represents the multiplier form of the problem to be solved.

Under constraints:

$$
\operatorname{MIN} \sum_{i=1}^{m} v_{i} x_{i k}-c_{k}
$$

$$
\sum_{i=1}^{m} v_{i} x_{i k}-\sum_{r=1}^{s} u_{r} y_{r j}-c_{k} \geq 0
$$

$$
\sum_{r=1}^{s} u_{r} y_{r k}=1
$$




$$
u_{r}, v_{i}>0 \quad \forall r=1, \ldots, s ; i=1, \ldots, m
$$

Where $v_{i}$ : The weighting coefficient of each input.

The duality rule in linear programming can be used to rewrite an equivalent form called "wrapped form". This is generally preferred since it contains only $\mathrm{s}+\mathrm{m}$ constraints instead of $\mathrm{n}+1$ of the multiplier form. Thus, the dual formula of the output-oriented VRS model is written:

$$
M A X \emptyset_{k}
$$

Under constraints:

$$
\begin{array}{lr}
\emptyset_{k} y_{r k}-\sum_{j=1}^{n} \lambda_{j} y_{r j} \leq 0 & r=1, \ldots, s \\
x_{i k}-\sum_{j=1}^{n} \lambda_{j} x_{i j} \geq 0 & i=1, \ldots, m
\end{array}
$$

$\sum_{j=1}^{n} \lambda_{j}=1$

$$
\lambda_{j} \geq \mathbf{0} \quad \forall j=1, \ldots, n
$$

Where

$\frac{1}{\phi_{k}}:$ The technical efficiency score;

$\lambda_{j}$ : The weighting coefficients which measure the capacity of each DMU (j) to constitute the benchmark.

The VRS model also helps to identify the nature of returns to scale (increasing or decreasing returns to scale) and the number of outputs that can be produced by each DMU using the same level of inputs.

\subsection{Malmquist Index}

Caves et al. (1982) proposed the Malmquist productivity index, which allows measuring productivity changes by distinguishing between efficiency changes and technical changes. This index, which has become a popular empirical tool, has several advantages, including taking into account several inputs and outputs as well as the non-necessity of having prices of inputs.

The Malmquist index calculates the distance ratio of each data point to a given technology and thus estimates total factor productivity change (TFP). Following the specifications given by Fare et al. (1994), the Malmquist index $\mathrm{M}$ for an output orientation is:

$$
M_{0}\left(x_{t}, y_{t}, x_{t+1}, y_{t+1}\right)=\left[\frac{D_{0}^{t}\left(x_{t+1}, y_{t+1}\right)}{D_{0}^{t}\left(x_{t}, y_{t}\right)} \times \frac{D_{0}^{t+1}\left(x_{t+1}, y_{t+1}\right)}{D_{0}^{t+1}\left(x_{t}, y_{t}\right)}\right]^{1 / 2}
$$


Or:

$M_{0}\left(x_{t}, y_{t}, x_{t+1}, y_{t+1}\right)=\frac{D_{0}^{t+1}\left(x_{t+1}, y_{t+1}\right)}{D_{0}^{t+1}\left(x_{t}, y_{t}\right)}\left[\frac{D_{0}^{t}\left(x_{t+1}, y_{t+1}\right)}{D_{0}^{t+1}\left(x_{t+1}, y_{t+1}\right)} \times \frac{D_{0}^{t}\left(x_{t}, y_{t}\right)}{D_{0}^{t+1}\left(x_{t}, y_{t}\right)}\right]^{1 / 2}$

Where:

$y_{t+1}, y_{t}$ : the vectors of the observed quantities of outputs for the periods $t+1$ and $t$ respectively;

$x_{t+1}, x_{t}:$ the vectors of the observed quantities of inputs for the periods $t+1$ and $\mathrm{t}$ respectively;

$D_{0}^{t}\left(x_{t}, y_{t}\right)$ : the output-oriented distance function at period $\mathrm{t}$;

$D_{0}^{t}\left(x_{t+1}, y_{t+1}\right)$ : the distance function, which measures the maximum proportional change in the output required to make $x_{t+1}, x_{t}$ and that relates to the technology of the period $t$.

$D_{0}^{t+1}\left(x_{t+1}, y_{t+1}\right)$ : the output-oriented distance function at the period $\mathrm{t}+1$;

$D_{0}^{t+1}\left(x_{t}, y_{t}\right)$ : the distance function, which measures the maximum proportional change in the output required to make $x_{t}, y_{t}$, in relation to the technology of the period $t+1$.

If the value of $M_{0}$ is greater than 1 , this shows a positive change in total factor productivity (TFP) between $t$ and $t+1$. Otherwise, if it is less than 1 , this means a negative productivity change.

From equation 15, it can be noticed that the first part of the equation measures the variation in efficiency between the periods $t$ and $t+1$, while the part inside the hooks measures technical change.

$$
\begin{gathered}
\text { TFP }=E F F C H \times T E C H C H \\
E F F C H=M_{0}\left(x_{t}, y_{t}, x_{t+1}, y_{t+1}\right)=\frac{D_{0}^{t+1}\left(x_{t+1}, y_{t+1}\right)}{D_{0}^{t+1}\left(x_{t} y_{t}\right)} \\
T E C H C H=\left[\frac{D_{0}^{t}\left(x_{t+1}, y_{t+1}\right)}{D_{0}^{t+1}\left(x_{t+1}, y_{t+1}\right)} \times \frac{D_{0}^{t}\left(x_{t}, y_{t}\right)}{D_{0}^{t+1}\left(x_{t} y_{t}\right)}\right]^{1 / 2}
\end{gathered}
$$

According to Fare et al. (1994), the efficiency change (EFFCH) is divided into two components; pure technical efficiency change $(\mathrm{PECH})$ and scale efficiency change $(\mathrm{SECH})$. Based on the presentation of these two indexes by Coelli and Prasada Rao (2005), the equations are as follows:

$$
\begin{gathered}
P E C H=\frac{D_{\text {ovrs }}^{t+1}\left(x_{t+1}, y_{t+1}\right)}{D_{\text {ovrs }}^{t}\left(x_{t}, y_{t}\right)} \\
S E C H=\left[\frac{D_{\text {ovrs }}^{t+1}\left(x_{t+1}, y_{t+1}\right) / D_{\text {ocrs }}^{t+1}\left(x_{t+1}, y_{t+1}\right)}{D_{\text {ovrs }}^{t+1}\left(x_{t}, y_{t}\right) / D_{\text {ocrs }}^{t+1}\left(x_{t}, y_{t}\right)} \times \frac{D_{\text {ovrs }}^{t}\left(x_{t+1}, y_{t+1}\right) / D_{o c r s}^{t}\left(x_{t+1}, y_{t+1}\right)}{D_{\text {ovrs }}^{t}\left(x_{t}, y_{t}\right) / D_{\text {ocrs }}^{t}\left(x_{t}, y_{t}\right)}\right]^{1 / 2}
\end{gathered}
$$

However, this reasoning has been the subject of several debates since the estimation of scale efficiency change supposes the use of the VRS specification and not CRS as proposed by Fare et al. (1994). Ray and Desli (1997) noted this contradiction and proposed another method of 
decomposition in which technological change was measured under VRS assumption. However, according to Coelli and Prasada Rao (2005), this method can generate some calculation difficulties when the distance functions are used. Indeed, inter-period calculations with the VRS specification is impractical.

According to Fare et al. (1994) and Coelli et al. (2005), the equation 14 can be estimated by calculating four distance functions relating to four linear programs, which are:

$$
\left[D_{0}^{t}\left(x_{t}, y_{t}\right)\right]^{-1}=\max _{\emptyset, \propto} \emptyset
$$

Under constraints:

Under constraints:

$$
\begin{gathered}
-\varnothing y_{i, t}+Y_{t} \propto \geq 0, \\
x_{i, t}-X_{t} \propto \geq 0, \\
\propto \geq 0, \\
{\left[D_{0}^{t+1}\left(x_{t+1}, y_{t+1}\right)\right]^{-1}=\max _{\emptyset, \alpha} \emptyset}
\end{gathered}
$$

$$
\begin{gathered}
-\varnothing y_{i, t+1}+Y_{t+1} \propto \geq 0, \\
x_{i, t+1}-X_{t+1} \propto \geq 0, \\
\propto \geq 0, \\
{\left[D_{0}^{t}\left(x_{t+1}, y_{t+1}\right)\right]^{-1}=\max _{\emptyset, \propto} \varnothing}
\end{gathered}
$$

Under constraints:

Under constraints:

$$
\begin{gathered}
-\varnothing y_{i, t+1}+Y_{t} \propto \geq 0, \\
x_{i, t+1}-X_{t} \propto \geq 0, \\
\propto \geq 0, \\
{\left[D_{0}^{t+1}\left(x_{t}, y_{t}\right)\right]^{-1}=\max _{\emptyset, \propto} \emptyset}
\end{gathered}
$$

Where:

$$
\begin{gathered}
-\emptyset y_{i, t}+Y_{t+1} \propto \geq 0, \\
x_{i, t}-X_{t+1} \propto \geq 0, \\
\propto \geq 0,
\end{gathered}
$$

$y_{i, t}$ : vector of the observed quantities of outputs of the DMU i (whose efficiency is measured) at period $t$;

$y_{i, t+1}$ : vector of the observed quantities of outputs of the DMU $i$ at the period $\mathrm{t}+1$

$x_{i, t}$ : vector of the observed quantities of DMU $\mathrm{i}$ inputs at period $\mathrm{t}$;

$y_{i, t+1}$ : vector of the observed quantities of DMU i inputs at the period $\mathrm{t}+1$;

$Y_{t}$ : matrix of observed quantities of outputs in period $t$;

$Y_{t+1}$ : matrix of observed quantities of outputs in period $t+1$;

$X_{t}$ matrix of the observed quantities of inputs at period $\mathrm{t}$; $X_{t+1}$ : matrix of the observed quantities of inputs at period $t+1$;

$\alpha$ : vector of weights measuring the capacity of each production unit to constitute the benchmark.

For the linear programs (23) and (24), the production points are compared at the border over another period and can obtain a value less than 1 
(even if they are LP oriented output). Besides, the four linear programs above must be calculated for each firm in the sample. Consequently, for $\mathrm{N}$ firms and $\mathrm{T}$ period, $\mathrm{N} *(3 \mathrm{~T}-2)$ linear programs have to be calculated in order to build a chain index (Coelli, 1996).

Finally, it should be noted that the Malmquist indexes are estimated through the DEA scores. Since other method of measuring the radial distance was used, such as Directional Distance Function, several authors (Grosskopf, 2003; Emrouznejad \& Yang, 2016) also suggest the use of the MalmquistLuenberger productivity indexes.

\subsection{Data}

The data were collected from different annual activity reports and statistical reports published by the Moroccan Ministry of Justice (http://www.justice.gov.ma/), as well as budgetary documents published by the Ministry of Economic and Finance.

The specification of input and output variables was based on the production process in place in Moroccan courts and the availability of data, as well as on the choices adopted in previous studies. The number of judges, the number of clerks and the staff expenses executed were used as inputs in this study, while the number of cases resolved formed a single output.

The Moroccan courts use human resources as their primary input, constituted by the judges who execute judicial tasks and clerks who execute the para-judicial and administrative tasks. In this context, the statistics show a significant change in the number of judges, going from 3,892 in 2013 to 4,219 in 2018, while the trend is reversed for clerk staff, which decreased by $4.6 \%$ from 14,864 in 2013 to 14,179 in 2018.

Regarding budgetary expenditure, it is difficult in the current system to have reliable data concerning all operating and investment expenditures executed by courts. This is the reason it is important to take into account only the expenditure related to the staff of each court. These expenses experienced a clear evolution of $23 \%$ between 2013 and 2018 mainly due to an increase in judges' salaries.

The only output used in our study is the number of cases resolved, regardless of their nature. This choice is guided by the fact that efforts made in courts are mainly aimed at the production of judgments or judicial decisions. Indeed, other efforts are made to execute judgments and decisions or to resolve conflicts by alternative methods. However, it is difficult for the moment to have reliable data concerning these aspects. Regarding the number of cases resolved, the statistics from the Ministry of Justice show an evolution of 20.3\% between 2013 and 2018.

For an overview of the data, Table 1 shows a descriptive statistics relating to the variables collected for the 110 courts studied (appeal courts, 
first instance courts, commercial courts, and administrative courts). The inputs are the number of judges and court clerks, and the court staff budget in millions of Dirhams, while the output variable is the number of resolved cases.

Table 1. Descriptive statistics

\begin{tabular}{|c|c|c|c|c|c|c|c|c|c|}
\hline & \multicolumn{4}{|c|}{2013} & \multicolumn{4}{|c|}{2018} \\
\hline & & \multicolumn{3}{|c|}{ Inputs } & \multirow{2}{*}{$\begin{array}{c}\text { Output } \\
\text { Resolved } \\
\text { cases } \\
\end{array}$} & \multicolumn{3}{|c|}{ Inputs } & \multirow{2}{*}{$\begin{array}{c}\text { Output } \\
\text { Resolved } \\
\text { cases }\end{array}$} \\
\hline & & Staff & Judges & Budget & & Staff & Judges & Budget & \\
\hline \multirow{4}{*}{$\begin{array}{l}\text { Appeal } \\
\text { Courts }\end{array}$} & Mean & 142 & 44 & 31,8 & 10714 & 144 & 45 & 39,1 & 13005 \\
\hline & Std dev & 74 & 35 & 19,8 & 8651 & 72 & 37 & 24,6 & 10990 \\
\hline & Min & 63 & 19 & 14,2 & 1451 & 65 & 18 & 16,7 & 2337 \\
\hline & Max & 351 & 169 & 92,6 & 37651 & 334 & 169 & 112,9 & 51041 \\
\hline \multirow{4}{*}{$\begin{array}{l}\text { First Instance } \\
\text { Courts }\end{array}$} & Mean & 110 & 35 & 24,9 & 30052 & 115 & 36 & 31,4 & 36376 \\
\hline & Std dev & 70 & 23 & 15,4 & 25578 & 75 & 26 & 20,8 & 34499 \\
\hline & Min & 39 & 11 & 8,3 & 2493 & 24 & 14 & 9,3 & 3036 \\
\hline & Max & 340 & 110 & 73,8 & 120053 & 351 & 110 & 93,1 & 175058 \\
\hline \multirow{4}{*}{$\begin{array}{c}\text { Commercial } \\
\text { Courts }\end{array}$} & Mean & 66 & 18 & 13,7 & 12665 & 57 & 21 & 16,8 & 12918 \\
\hline & Std dev & 28 & 13 & 7,7 & 19223 & 31 & 16 & 10,8 & 20674 \\
\hline & Min & 37 & 7 & 8,8 & 2279 & 34 & 10 & 9,4 & 2407 \\
\hline & Max & 134 & 51 & 33,3 & 69336 & 135 & 63 & 45,4 & 74442 \\
\hline \multirow{4}{*}{$\begin{array}{c}\text { Administrative } \\
\text { Courts }\end{array}$} & Mean & 47 & 15 & 10,6 & 3048 & 43 & 19 & 14,0 & 4657 \\
\hline & Std dev & 19 & 7 & 4,3 & 2145 & 23 & 11 & 7,9 & 3744 \\
\hline & Min & 24 & 9 & 5,9 & 1280 & 21 & 9 & 6,7 & 1379 \\
\hline & Max & 78 & 28 & 18,8 & 6363 & 88 & 39 & 28,3 & 12281 \\
\hline
\end{tabular}

Through statistics of input variables, the average of judges per court increased sharply between the two years for specialized courts, while it remained almost stable for the first instance and appeal courts. This shows the effort made in terms of human resources investment to manage pending cases in the administrative and commercial courts. On the other hand, this trend is reversed for the administrative staff. Its number has remained almost stable for the courts of general jurisdiction and has decreased for the specialized courts. The evolution of the budget followed the same trend as the staff, with a significant increase for all courts.

Regarding the output variable, the data show a significant increase in the average of resolved cases in first instance courts, appeal courts, and administrative courts, while it has remained stable for commercial courts. The maximum value has increased significantly for all courts and even doubled for administrative courts. Analysis of this data using the DEA method and the Malmquist index led to the results presented in the following section.

\section{Results and Discussion}

The Moroccan judicial system underwent a significant reform from 2013, which mobilized a significant investment in human and financial 
resources. Therefore, this study's results show to what extent the implementation of this reform has influenced the efficiency of courts. Also, the findings of the study will be presented and discussed in this section. The average efficiency of each group of courts and the number of efficient ones will be calculated. Thereafter, the results of returns to scale and the frequency of appearance in the peer group will be presented. After that, the potential inputs and outputs gains is shown. Finally, the results related to average productivity change will also be presented. All the measures listed in the tables below have been obtained by using the Win4Deap software.

Table 2 shows the average efficiency scores and the minimum and maximum values obtained for each group of courts in 2013 and 2018. The CRS efficiency scores are decomposed into pure technical efficiency scores (VRS) and scale efficiency scores.

Table 2. Summary statistics for DEA efficiency scores

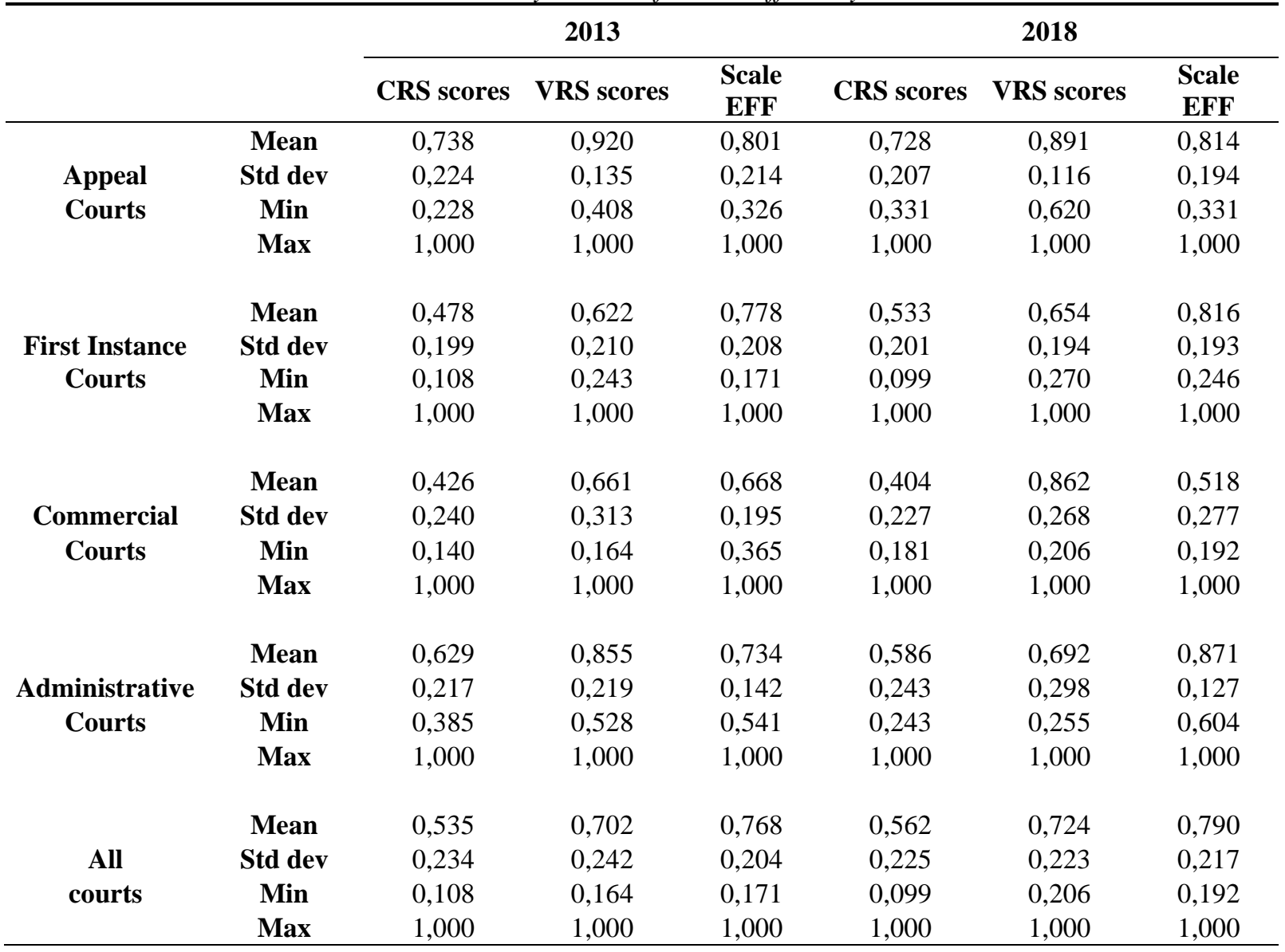


The results show that the average level of CRS efficiency of Moroccan courts is relatively low during the period studied, with a level of around 53.5\% in 2013 and an improvement in 2018 to reach 56.2\%.

The decomposition of CRS efficiency shows that this improvement is also valid for VRS and scale efficiency. On the other hand, the average scores and the trend of evolution are variable according to the type of courts.

In this sense, appeal and commercial courts had the highest VRS pure technical efficiency scores in 2018, which is against low levels for the first instance and administrative courts. On the other side, apart from the commercial courts, which have a low scale efficiency score, all the other courts have improved their scale efficiency between the two years.

The data in Table 3, relating to the number of efficient courts for the two years, also shows that the number of CRS efficient courts has barely reached 7 courts out of 110 . However, there was a clear improvement in the number of first instance courts that reached the efficiency frontier in 2018, mainly due to improved scale efficiency.

These observed average levels of efficiency show that the courts generally have a large margin to improve the number of cases resolved while maintaining the same level of human and financial resources used. Several previous studies also confirm this result. For instance, Major (2015) studied efficiency courts in Poland, while Nissi and Rapposelli (2011) studied Italian courts and also stated that only three courts are efficient with CRS specification, against 13 with VRS specification. On the other hand, the significant difference between the CRS and VRS scores confirms the presence of variable returns to scales, hence the relevance of the choice of the VRS model to examine the scale efficiency.

Table 3. Frequency of efficient courts

\begin{tabular}{|c|c|c|c|c|c|c|c|}
\hline & \multicolumn{4}{|c|}{2013} & \multicolumn{3}{|c|}{2018} \\
\hline & $\begin{array}{c}\text { Total } \\
\text { Number }\end{array}$ & $\begin{array}{l}\text { CRS } \\
\text { EFF }\end{array}$ & $\begin{array}{l}\text { VRS } \\
\text { EFF }\end{array}$ & $\begin{array}{l}\text { Scale } \\
\text { EFF }\end{array}$ & $\begin{array}{l}\text { CRS } \\
\text { EFF }\end{array}$ & $\begin{array}{l}\text { VRS } \\
\text { EFF }\end{array}$ & Scale EFF \\
\hline Appeal Courts & 21 & 2 & 9 & 2 & 2 & 7 & 2 \\
\hline $\begin{array}{c}\text { First Instance } \\
\text { Courts }\end{array}$ & 69 & 2 & 7 & 2 & 3 & 8 & 8 \\
\hline Commercial Courts & 11 & 1 & 4 & 1 & 1 & 6 & 1 \\
\hline $\begin{array}{l}\text { Administrative } \\
\text { Courts }\end{array}$ & 9 & 1 & 6 & 1 & 1 & 3 & 1 \\
\hline All Courts & 110 & 6 & 26 & 6 & 7 & 24 & 12 \\
\hline
\end{tabular}

It is also apparent that not all courts operate on an optimal production scale. The inefficiency of first instance and administrative courts is mainly due to pure technical inefficiency, which is a sign of inadequate resources allocation. On the other hand, for commercial courts, the low values of their scale efficiency (51.8\% in 2018) and the high values of VRS efficiency 
(86.2\%) show that their inefficiency is due to inadequate production scales. These results can be explained by analyzing the nature of returns to scale.

In this context, according to the results showed in Table $4,73.6 \%$ of the courts are operating under increasing returns to scale. This means that outputs can be increased by a higher proportion than the increase in inputs. At the same time, the proportion of the courts operating under decreasing returns to scale decreased significantly in 2018 in favour of the increase in courts operating under constant or increasing returns. However, the commercial courts registered no change during the two years of our study.

Table 4. Frequency of returns to scale

\begin{tabular}{ccccccc}
\hline & \multicolumn{3}{c}{$\mathbf{2 0 1 3}$} & \multicolumn{3}{c}{$\mathbf{2 0 1 8}$} \\
\cline { 2 - 7 } & CRS & IRS & DRS & CRS & IRS & DRS \\
\hline Appeal Courts & $9,5 \%$ & $66,7 \%$ & $23,8 \%$ & $9,5 \%$ & $61,9 \%$ & $28,6 \%$ \\
First Instance Courts & $2,9 \%$ & $63,8 \%$ & $33,3 \%$ & $11,6 \%$ & $81,2 \%$ & $7,2 \%$ \\
Commercial Courts & $9,1 \%$ & $90,9 \%$ & $0,0 \%$ & $9,1 \%$ & $90,9 \%$ & $0,0 \%$ \\
Administrative Courts & $11,1 \%$ & $66,7 \%$ & $22,2 \%$ & $11,1 \%$ & $22,2 \%$ & $66,7 \%$ \\
All Courts & $5,5 \%$ & $67,3 \%$ & $27,3 \%$ & $10,9 \%$ & $73,6 \%$ & $15,5 \%$ \\
\hline
\end{tabular}

These results confirm our earlier observation that most courts do not operate at the optimal scale, and most can still increase their productivity. Indeed, the courts that operate under increasing returns to scale all have an interest in increasing their inputs (judges, clerks, and operating expenses) to benefit from economies of scale and thus reduce pending cases. However, it is important to note that increasing inputs is limited by the means that one court can deploy.

Returning to the case of commercial courts which recorded a very low scale efficiency, it was found that $90.9 \%$ of these courts operate under increasing returns to scale. This means that they are far from reaching an adequate production scale. Indeed, the nature and quantity of the cases handled by commercial courts are linked to the development of the economic activity. This is why it is, for example, difficult for Moroccan courts to reach the same productivity level as the commercial court in the city of Casablanca, which gathers a significant part of the economic activity of the country. In addition, they have more qualified and experienced skills in business affairs.

For the nine administrative courts that cover the country's whole territory, they are at $66.7 \%$ under decreasing returns to scale. Thus, as the cases registered in these courts increase, it is no longer possible to increase the inputs to settle more cases. In this case, it is better to create other small administrative courts in other cities to absorb new affairs flows.

Our analysis also identified a reference group for each inefficient court, including a set of efficient courts with similar characteristics. In 2018, it turned out that BeniMellal appeal court, Agadir first instance court, 
Casablanca commercial court, and the administrative court of Rabat were at the top of the list of references for all the courts. Indeed, they were most frequently identified as benchmarks among all the efficient courts of the group. Their efficiency is sustainable in addition to being progressively improved between 2013 and 2018. This large number of citations in the reference groups can be interpreted as a sign of the robustness of the units with best practices (Nissi \& Rapposelli, 2011).

Consequently, the courts that are most cited in the reference groups are located in the major cities of the country, in particular Casablanca, which registers the highest number of cases, and Rabat, which is the first in terms of administrative cases registered. This result is also in line with the study of Pedraja-Chaparro and Salinas-Jimenez (1996), which focused on Spanish courts and demonstrated that there is a remarkable degree of specialization in big cities like Madrid and Barcelona. It is, therefore, logical to assume that the specialization of these courts must increase their productivity, and that the large courts is considered as the most efficient.

Reference groups are also used to determine potential productivity gains from inefficient courts if they become efficient. Table 5 presents the rates representing the average potential gains by groups of courts in 2018 that can be made in terms of the number of judges, clerks, and cases resolved.

Table 5. Proportion of potential court inputs and outputs gains

\begin{tabular}{cccc}
\hline & Clerks & Judges & Resolved cases \\
\hline Appeal Courts & $-9,0 \%$ & $0,0 \%$ & $11,3 \%$ \\
First Instance Courts & $-5,1 \%$ & $-6,1 \%$ & $47,4 \%$ \\
Commercial Courts & $-1,0 \%$ & $0,0 \%$ & $30,0 \%$ \\
Administrative & & & \\
Courts & $-15,7 \%$ & $-1,5 \%$ & $38,1 \%$ \\
All Courts & $-6,2 \%$ & $-4,0 \%$ & $43,1 \%$ \\
\hline
\end{tabular}

From the results obtained, it can be seen that all courts have wide marge to increase the number of cases resolved. For example, the cases resolved by the first instance courts can improve by $47.4 \%$, representing more than 1190688 cases, provided they are well-managed and allocate the means to maximize potential profit in terms of productivity, as pointed out by Boyne (2003).

Also, the possible gains in terms of the number of judges are less significant than the clerks. This is more important for administrative courts, where the number of clerks can be reduced significantly. On the other hand, the commercial courts have tiny gains to make regarding the number of clerks and judges. Therefore, they must improve their internal process to gain productivity and resolve more cases.

That said, one should pay attention to all of these potential gains from a theoretical point of view. Indeed, these results provide crucial information 
on the managerial orientation to be taken, that of the possible rate of staff in a given court. However, it is still necessary to consider some essential criteria, especially the fact that the performance of judges and clerks is not the same, depending on their age, skills, experience, and other criteria. Besides, the working climate in the court can also affect performance, for example, the level of motivation of clerks, the availability of resources, or other variables. Therefore, a set of variables must be taken into account when reducing the resources allocated to a court.

To continue the analysis, the Malmquist index proposed by Fare et al. (1994) was used to measure the productivity change in courts during the period of implementation of the national justice reform charter from 2013 to 2018. During this period, there was a mobilization of significant human and financial means to implement the reform.

Therefore, Table 6 shows the average scores of efficiency change $(\mathrm{EFFCH})$, decomposed into pure efficiency change $(\mathrm{PECH})$ and scale efficiency change (SECH), as well as that of technical change (TECHCH) and the total factor productivity change (TFPCH). Table 7 shows the proportion of courts having recorded a positive evolution between the two years studied.

Table 6. Average productivity change between 2013 and 2018

\begin{tabular}{cccccc}
\hline & EFFCH & TECHCH & PECH & SECH & TFPCH \\
\hline Appeal Courts & 1,000 & 1,138 & 0,975 & 1,026 & 1,139 \\
First Instance Courts & 1,126 & 0,928 & 1,062 & 1,061 & 1,046 \\
Commercial Courts & 0,978 & 0,880 & 1,387 & 0,705 & 0,860 \\
Administrative Courts & 0,903 & 1,336 & 0,756 & 1,193 & 1,206 \\
All Courts & 1,002 & 1,071 & 1,045 & 0,996 & 1,063 \\
\hline
\end{tabular}

The results show that the total productivity factors index of the Moroccan courts developed positively between 2013 and 2018 by $6.3 \%$. This improvement is mainly due to a positive technical change of $7.1 \%$, against a slight change in technical efficiency of $0.2 \%$. This weakness in the evolution of technical efficiency is due to a deterioration in scale efficiency by $0.4 \%$.

Concerning the group's results, the evolution of the average indexes of all the groups was positive except for the commercial courts, which recorded a negative evolution due to technical regression at the same time. It should also be noted that technical efficiency of administrative courts evolved negatively by $9.7 \%$, but it was offset by the consequent development in technical change, which reached $33.6 \%$.

The results relating to the number of courts having recorded a positive evolution show that the Moroccan courts have become more efficient, from a technical point of view, apart from the commercial courts that recorded a deterioration. 
Table 7. Average proportion of courts with positive productivity growth

\begin{tabular}{cccccc}
\hline & EFFCH & TECHCH & PECH & SECH & TFPCH \\
\hline Appeal Courts & $51 \%$ & $75 \%$ & $39 \%$ & $49 \%$ & $64 \%$ \\
First Instance Courts & $52 \%$ & $58 \%$ & $48 \%$ & $46 \%$ & $55 \%$ \\
Commercial Courts & $40 \%$ & $40 \%$ & $29 \%$ & $33 \%$ & $35 \%$ \\
Administrative Courts & $42 \%$ & $56 \%$ & $27 \%$ & $51 \%$ & $60 \%$ \\
\hline
\end{tabular}

The analysis of Malmquist's indexes, therefore, showed that the period of implementation of the national charter for the reform of the judicial system experienced improved productivity in the majority of Moroccan courts. This improvement is mainly due to technical change, which means that the measures implemented to computerize the courts and simplify procedures have positively affected the efficiency frontier that shifts up.

The change in technical efficiency was also preponderant in first instance courts, which moved closer to the efficiency frontier. However, efforts remain to be deployed for commercial courts.

The individual results obtained for each court will help guide court managers about the provisions to be implemented, and on what they must align themselves with in order to improve their productivity.

After analyzing the results of the efficiency and productivity change of the Moroccan courts, one can wonder about the public policies that can be adopted in this situation. Here, two policies that can be envisaged to improve efficiency is cited. However, the results differences between courts suggest the non-generalization of the same solutions for all courts and decisionmaking on a case-by-case basis.

The first policy consists of increasing the number of judges and clerks to take advantage of economies of scale. It is, therefore, a matter of the courts operating under increasing returns to scale, which excludes the majority of administrative courts.

However, this policy has drawn criticism from several researchers. Even if the courts are an intensive labor activity, in which judges play an important role, improving productivity by increasing their number may not produce the expected result. According to Beenstock and Haitovsky (2004), the increase in the number of judges is not helpful due to the judges' aversion of their effort. Consequently, an increase in judges' number will decrease their individual efforts (Posner, 1993). On the other hand, the increase in court inputs is not always easy financially, especially for a developing country like Morocco that is trying to rationalize its expenses and also those relating to the payroll. An intermediate choice can then be adopted by focusing intervention on the courts, which suffers from a significant number of pending cases.

The other possible policy is to improve productivity through technical change. Indeed, it is not enough to improve the efficiency of the courts 
compared to a stable frontier. It is necessary that this frontier should also be improved. This can be done in different ways, such as the generalization of information systems, the simplification of procedures, the implementation of alternative dispute resolution procedures, or even the motivation of judges and clerks to become more productive. However, a study of these different factors must be carried out to identify the determinants of efficiency in the context of Moroccan courts in order to facilitate the determination of the actions to be taken to drive effective technical change.

\section{Conclusion}

This study aimed to measure and explain the efficiency of 110 Moroccan courts and their productivity change during the period of implementation of the judicial reform charter between 2013 and 2018.

The use of the DEA method under an output orientation allows us to measure the efficiency of each type of court separately and to identify the courts constituting a benchmark for the inefficient ones. The Malmquist index allows the measurement of the efficiency change and the technical change during the same period.

The literature review showed few previous studies on measuring efficiency in the courts, especially in developing countries. This study is the first one in Morocco and will contribute to understanding the effect of judicial reform in terms of efficiency and productivity.

In this sense, the results have shown that the Moroccan courts have a wide margin to improve their efficiency. The average efficiency level is relatively low, with $53.5 \%$ under the CRS assumption and $70.2 \%$ under the VRS assumption. Appeal courts are the most technically efficient, and first instance courts are the least efficient. Regarding returns to scale, most courts operate under increasing scales, which means that they can further increase their productivity by taking advantage of economies of scale. Administrative courts are the exception, with a majority under decreasing returns to scales, implying the need to divide these courts into several entities.

The results of productivity change show that the implementation of the judicial reform charter had a positive impact on the total factor productivity of the courts of $6.3 \%$. This improvement is due to a positive technical change of $7.1 \%$. However, the productivity of the commercial courts fell by $14 \%$. These results imply the adoption of corrective measures for inefficient courts, either by increasing the number of judges and court clerks to benefit from economies of scale or by improving the productivity of the judicial staff by modernizing processes and simplifying procedures or motivation incentives.

On the other hand, this research can be extensible in several ways to overcome its current limitations. It is thus possible to integrate other variables in the efficiency measurement model, such as the number of pre-judicial cases, 
to consider the efforts made by the king's prosecutors in resolving conflicts using conciliation methods. It is also possible to use other methods to identify the determinants of efficiency or measure efficiency following changes in the judicial map. Indeed, in 2018, many courts were abolished or created. Therefore, it is essential to assess the impact of this reform on the courts' productivity and draw conclusions that can help decision-makers to make future changes in the judicial map.

In general, it appears that the field of research relating to efficiency measurement still arouses the scientific community's interest, especially since the public sector in developing countries has least being explored to the best of our knowledge. As a result, this sector deserves to be studied. This gap can be reduced by using different methods and different research protocols to guide public decision-makers better and provide recommendations that can contribute to the development of this sector.

\section{References:}

1. Arjomandi, A., Salleh, M. I., and Mohammadzadeh, A. (2015). Measuring productivity change in higher education: an application of Hicks-Moorsteen total factor productivity index to Malaysian public universities. Journal of the Asia Pacific Economy, 20(4):630-643.

2. Banker, R., Charnes, A., and Cooper, W. (1984). Some models for estimating technical and scale inefficiencies in Data Envelopment Analysis. Management Science, 30(9):1078-1092.

3. Beenstock, M. and Haitovsky, Y. (2004). Does the appointment of judges increase the output of the judiciary? International Review of Law and Economics, 24(3):351-369.

4. Boyne, G. A. (2003). Sources of Public Service Improvement: A Critical Review and Research Agenda. Journal of Public Administration Research and Theory, 13(3):367-394.

5. Caves, D. W., Christensen, L. R., and Diewert, W. E. (1982). The Economic Theory of Index Numbers and the Measurement of Input, Output, and Productivity. Econometrica, 50(6):1393.

6. Charnes, A., Cooper, W., and Rhodes, E. (1978). Measuring the efficiency of decision making units. European Journal of Operational Research, (2):429-444.

7. Coelli, T. (1996). A guide to deap version 2.1: a data envelopment analysis (computer) program. Centre for Efficiency and Productivity Analysis, University of New England, Australia, 96(08).

8. Coelli, T. and Prasada Rao, D. (2005). Total factor productivity growth in agriculture: A Malmquist index analysis of 9 countries, 1980-2000. Agricultural Economics, 32(1):15-34. 
9. Coelli, T., Rao, D., O'Donnell, C., and Battese, G., editors (2005). An introduction to efficiency and productivity analysis. Springer, New York, 2nd edition.

10. Cooper, W. W., Seiford, L. M., and Tone, K. (2001). Data envelopment analysis: A comprehensive text with models, applications, references and deasolver software. Journal-operational Research Society, 52(12):1408-1409.

11. Dalla Pellegrina, L. (2008). Court delays and crime deterrence: An application to crimes against property in Italy. European Journal of Law and Economics, 26(3):267-290.

12. Dam, K. W. (2006). The judiciary and economic development. U Chicago Law and Economics, Olin Working Paper, (287).

13. Debreu, G. (1951). The Coefficient of Resource Utilization. Econometrica, 19(3):273.

14. El Bialy, N. (2011). Measuring judicial performance (The Case of Egypt). German Working Papers in Law and Economics, (Paper No. 14-2011).

15. Elbialy, N. and Garcia-Rubio, M. A. (2011). Assessing judicial efficiency of Egyptian first instance courts: A DEA analysis. Joint Discussion Paper Series in Economics, (no. 19-2011):30.

16. Emrouznejad, A. and Yang, G.-1. (2016). CO2 emissions reduction of Chinese light manufacturing industries: A novel RAM-based global malmquist luenberger productivity index. Energy Policy, 96:397-410.

17. Falavigna, G., Ippoliti, R., and Ramello, G. B. (2018). DEA-based Malmquist productivity indexes for understanding courts reform. Socio-Economic Planning Sciences, 62:31-43.

18. Fare, R., Grosskopf, S., Norris, M., and Zhang, Z. (1994). Productivity growth, technical progress, and efficiency change in industrialized countries. The American Economic Review, 84(1):66\{83.

19. Farrell, M. J. (1957). The Measurement of Productive Efficiency. Journal of the Royal Statistical Society. Series A (General), 120(3):253.

20. Ferrandino, J. (2012). The Impact of Revision 7 on the Technical Efficiency of Florida's Circuit Courts. Justice System Journal, $33(1): 22-46$.

21. Finocchiaro Castro, M. and Guccio, C. (2014). Searching for the source of technical inefficiency in Italian judicial districts: an empirical investigation. European Journal of Law and Economics, 38(3):369-391.

22. Giacalone, M., Nissi, E. and Cusatelli, C. (2020). Dynamic efficiency evaluation of Italian judicial system using DEA based Malmquist 
productivity indexes, Socio-Economic Planning Sciences, Elsevier, 72(C).

23. Grosskopf, S. (2003). Some Remarks on Productivity and its Decompositions. Journal of Productivity Analysis, 20(3,):459-474.

24. Ippoliti, R. and Tria, G. (2020). Efficiency of judicial systems: model definition and output estimation, Journal of Applied Economics, 23(1):385-408, DOI: 10.1080/15140326.2020.1776977.

25. Johnes, J. (1996). Theory and Methodology: Performance assessment in higher education in Britain. (89):18-33.

26. Johnes, J. (2004). Efficiency measurement. In International Handbook on the Economics of Education. Edward Elgar Publishing Ltd, Cheltenham.

27. Johnes, J. (2006). Data envelopment analysis and its application to the measurement of efficiency in higher education. Economics of Education Review, 25(3):273-288.

28. Kittelsen, S. A. and Forsund, F. R. (1992). Efficiency analysis of Norwegian district courts. Journal of Productivity Analysis, 3(3):277306.

29. Koopman, T. (1951). An Analysis of Production as an Efficient Combination of Activities. activity analysis of production and Allowance, John Wiley and Sons, Inc. (Monograph No. 13).

30. Lewin, A. Y., Morey, R. C., and Cook, T. J. (1982). Evaluating the administrative efficiency of courts. Omega, 10(4):401-411.

31. Lim, H.-E. and Md. Taib, F. (2016). How Efficient are Malaysian Public Universities? A Comparative Analysis Using Data Envelopment Analysis. Asian Academy of Management Journal, 21(2):75-97.

32. Liu, J. S., Lu, L. Y., Lu, W.-M., and Lin, B. J. (2013). Data envelopment analysis 1978-2010: A citation-based literature survey. Omega, 41(1):3-15.

33. Major, W. (2015). Data Envelopment Analysis as an instrument for measuring the efficiency of courts. Operations Research and Decisions, (4):19-34.

34. Mattsson, P., Mansson, J., Andersson, C., and Bonander, F. (2018). A bootstrapped Malmquist index applied to Swedish district courts. European Journal of Law and Economics, 46(1):141-142.

35. Nissi, E., Giacalone, M. and Cusatelli, C. (2019). The Efficiency of the Italian Judicial System: A Two Stage Data Envelopment Analysis Approach, Social Indicators Research: An International and Interdisciplinary Journal for Quality-of-Life Measurement, Springer, 146(1): 395-407. 
36. Nissi, E. and Rapposelli, A. (2011). A data envelopement analysis of Italian courts efficiency. Italian Journal of Applied Statistics, 22(2):199-210.

37. Pedraja-Chaparro, F. and Salinas-Jimenez, J. (1996). An assessment of the efficiency of Spanish Courts using DEA. Applied Economics, 28(11):1391-1403.

38. Posner, R. A. (1993). What Do Judges and Justices Maximize? (The Same Things Everyone Else Does). Supreme Court Economic Review, (3):1-41.

39. Ray, S. C. and Desli, E. (1997). Productivity Growth, Technical Progress, and Efficiency Change in Industrialized Countries: Comment. The American Economic Review, 87(5):1033-1039.

40. Rosales-Lopez, V. (2008). Economics of court performance: an empirical analysis. European Journal of Law and Economics, 25(3):231-251.

41. Schneider, M. R. (2005). Judicial career incentives and court performance: an empirical study of the German labour courts of appeal. European Journal of Law and Economics, 20(2):127-144.

42. Sherman, H. and Zhu, J. (2006). Service productivity management: Improving service performance using data envelopment analysis (DEA). Springer science \& business media, New York.

43. Simar, L. and Wilson, P. W. (2015). Statistical approaches for nonparametric frontier models : a guided tour. International Statistical Review, 83(1):77-110.

44. Tsai, C.-F. and Tsai, J.-H. (2010). Performance Evaluation of the Judicial System in Taiwan Using Data Envelopment Analysis and Decision Trees. In 2010 Second International Conference on Computer Engineering and Applications, pages 290-294, Bali Island, Indonesia. IEEE.

45. Voigt, S. (2016). Determinants of judicial efficiency: a survey. European Journal of Law and Economics, 42(2):183-208.

46. World Bank (2003). Legal and judicial reform: Strategic directions. [online] Technical report 26916, Washington, DC. http://documents.worldbank.org/curated/en/218071468779992785/le galand-judicial-reform-strategic-directions (Accessed 23 Mars 2020).

47. Yeung, L. (2018). Measuring Efficiency of Brazilian Courts: One Decade Later. SSRN Electronic Journal, [online] https://www.ssrn.com/abstract=3200588 (Accessed 25 November 2019).

48. Yeung, L. L. and Azevedo, P. F. (2011). Measuring efficiency of Brazilian courts with data envelopment analysis (DEA). IMA Journal of Management Mathematics, 22(4):343-356. 